\title{
Verbing and Linguistic Innovation
}

\author{
Laura A. Michaelis * and Allen Minchun Hsiao \\ University of Colorado Boulder, Boulder, CO, United States
}

Denominal verbs are produced by a syntactic category shift, conversion, in which the word's inflectional and combinatory potential change while its internal composition does not (Valera, 2015: 322). Perhaps no language owes as many of its verbs to the conversion strategy as English (Koutsoukos, 2021), the majority being denominal (noun-derived) verbs, e.g., Widespread seedless cultivars typically fruit twice yearly in the Caribbean. Denominal conversion has been the predominant method of verb creation since the 13th century (Gottfurcht, 2008), with the result that denominal verbs present a continuum of conventionality ranging from conventional verb-phrase replacements like paint, trash, pocket, mother to evanescent innovations like adulting and criming. Language users must rely on certain inferential strategies to figure out what novel denominal verbs mean, combining information from multiple sources, including salient properties of the source noun's denotatum, the event structure of the clause in which that noun serves as a

\section{OPEN ACCESS}

Edited by: Mike Putnam,

Pennsylvania State University (PSU), United States

Reviewed by:

Pablo E. Requena, University of Texas at San Antonio, United States

Matthew Carlson, Pennsylvania State University (PSU), United States

*Correspondence:

Laura A. Michaelis laura.michaelis@colorado.edu

Specialty section: This article was submitted to Language Sciences,

a section of the journal Frontiers in Communication

Received: 10 September 2020 Accepted: 15 June 2021 Published: 08 July 2021

Citation: Michaelis LA and Hsiao AM (2021) Verbing and Linguistic Innovation.

Front. Commun. 6:604763. doi: $10.3389 /$ fcomm.2021.604763 predicator, and socio-cultural knowledge. How exactly does this work? Our answer recalls the major lessons of Clark and Clark's seminal 1979 paper "When Nouns Surface as Verbs": denominal verbs have context-dependent rather than fixed meanings, and their interpretations rely on cooperation between speaker and hearer. These are lessons seemingly forgotten by proponents of recent, influential derivation-based accounts, which leverage the formal similarity between denominal verbs and noun-incorporating verbs like backstab and manspread. While, as discussed here, syntacticized approaches to semantic representation fail to account for the interpretive latitude that denominal verbs actually display, there are reasons to reject a strong view of context dependence as well. For Clark and Clark, interpretations of innovative denominal verbs either directly reflect criterial features of their source nouns or are ad hoc, derived from "moment-to-moment cooperation," including gestures, allusions, and "other momentarily relevant facts about the conversation" (1979: 783). We argue that denominal interpretations are more tightly regulated, and involve reconciling the results of four distinct interpretive strategies: nominal frame computation, verb-construction integration, co-composition and, finally, conceptual blending. To describe these interpretive strategies, we bring to bear a suite of analytic tools developed to model everyday language understanding: Construction Grammar (Michaelis, 2004; Goldberg, 2006; Michaelis, 2011), enriched composition (Pustejovsky, 1998; Pustejovsky, 2012), Conceptual Blending Theory (Fauconnier and Turner, 2004), and Frame Semantics (Fillmore, 2006; Andor, 2010). In line with Clark and Clark's (1979) convention for the interpretation of innovative denominal verbs, we argue that nouns used in innovative denominal formations are chosen based on relational properties of entities denoted by those nouns, whether common or proper (e.g., shape, behavior, composition, 
use, provenance). At the same time, the descriptive framework that we propose leaves fewer interpretive factors to vagaries of context.

Keywords: frame semantics, denominal verbs, lexical semantics, argument structure, linguistic innovation, conceptual blending, construction grammar

\section{INTRODUCTION}

In the approach to meaning taken by Grice (1957), Grice (1989) and other proponents of ordinary language philosophy, acts, including linguistic acts (utterances), are meaningful insofar as they are performed with intention. In Grice's account, it is the audience's recognition of the intention behind a linguistic act that gives it its meaning. This account is vulnerable to the "Humpty Dumpty objection": an utterance cannot be used to mean whatever the utterer wants it to (Batty, 2008); both the words and the structure of the sentence play a key role in its successful interpretation, particularly if it is novel or non-formulaic. At the same time, however, word meaning shifts are a staple of language play and verbal art. As Grice observes, "what a speaker or writer means by a sign on a particular occasion. . .may well diverge from the standard meaning of the sign" (1989: 197). This article suggests that determining the meaning of a novel sentence, in particular one containing a novel denominal verb, requires the interpreter to weigh intrinsic evidence (lexical meaning) against extrinsic evidence (syntactic context, utterance context, mutual knowledge).

A denominal verb is the product of a syntactic category shift (from noun to verb). It refers to a state, event or process that involves an instance of the class of entities denoted by the source noun. The derived word's status as a verb is signaled indirectly-by its inflectional and combinatory behavior rather than by its internal composition. For example, in Colin watered his neighbors' plants we know that watered is a verb both because it contains the past-tense ending -ed and occupies the head-word slot in the VP watered his neighbors' plants. This covert strategy is sometimes referred to as conversion: "a word-formation process where the form of the converted item does not change, while its inflectional potential, its syntactic function and its meaning do, such that the item displays inflectional, syntactic and semantic properties of a new word class" (Valera, 2015: 322). Perhaps no language owes as many of its verbs to the conversion strategy as English does (Koutsoukos, 2021). Denominal conversion has been the preeminent way we coin verbs since the $13^{\text {th }}$ century (Gottfurcht, 2008). But conversion does not always yield new verbs. A denominal verb is just as likely to be a nonce formation-never to reappear. Novel denominal formations are often vehicles for humor, figuration, caricature and social commentary-sometimes all at the same time. On August 13, 2020, comedian George Wallace posted the tweet shown in (1):

\footnotetext{
1. Teorge Wallace $\$$ MrGeorgeWallace · Aug 13 I have pre-written over 8,000 tweets so I can Herman Cain the shit outta this place in the event of my demise and whatnot. Q 3344 七 $3.6 \mathrm{~K} \quad \bigcirc 49.6 \mathrm{~K}$ $\uparrow$
}

The nonce verb Herman Cain is unlikely to outlive the curious episode alluded to in Wallace's tweet: for weeks after his death from coronavirus (contracted at a Trump rally), business man and Tea Party activist Herman Cain continued to "tweet from the grave", in one instance expressing doubt about the deadliness of the virus. For our purposes, what is interesting about the nonce eponymous verb Herman Cain is that it is allusive, evoking, through its syntax, idiomatic expressions of "laying waste", e.g., blast/tear/smash the $x$ out of $y$ (Schönefeld 2018). While using an unconventional verb, Wallace nonetheless relies on conventions about the use of language (Searle, 1975; Morgan, 1978). Clark and Clark's innovative denominal verb convention (IDVC; 1979: 787) captures such a convention of use:

In using an innovative denominal verb sincerely, [a] speaker means to denote

(a) the kind of situation

(b) that [they have] good reason to believe

(c) that on this occasion the listener can readily compute

(d) uniquely

(e) on the basis of their mutual knowledge

(f) in such a way that the parent noun denotes one role in the situation, and the remaining surface arguments of the denominal verb denote other roles in the situation.

When the "parent noun" is a proper noun, as in (1), Clark and Clark say that it is a contextual expression rather than a denotational one, because its meaning relies on shared knowledge about known persons and circumstances, and not properties intrinsic to the class of entities denoted by the parent noun (1979: 785). At the same time, however, the proper noun Herman Cain does not simply name a famous person; in the context of (1) it is a relational noun-meaningful only inasmuch as it serves to conjure the components of an act of retribution (the offense, the betrayers, the act of betrayal, the act of vengeance). What this suggests is that a noun (or other word) has the import it does when deployed in sentence not because of criterial properties of category referred to, but rather because of the scenes in which we can imagine entities of this type playing a role (Fillmore 1976). Accordingly, our approach to the meaning of denominal verbs is based on the frame-semantic framework developed by Charles Fillmore. Fillmore, 1969 (163) suggests that nouns and verbs have analogous arrays of semantic dependents and therefore denote similar situations (the basis of the FrameNet lexicon ${ }^{1}$ that he later developed). Take, for example, the Framenet frame REVENGE, which includes the following frame elements (FEs): Offender, Injured party, Avenger and Punishment. Fillmore observes:

The words that evoke [the REVENGE] frame include simple verbs like avenge, revenge, retaliate; phrasal verbs like pay back;

\footnotetext{
${ }^{1}$ See the Framenet indices at https://framenet.icsi.berkeley.edu/fndrupal/.
} 
TABLE 1 | Categories of English denominal verbs (based on Gottfurcht 2008: 100).

\begin{tabular}{|c|c|c|}
\hline Class & Event structure & Example \\
\hline Result & x causes y to become [source-noun'] & I powdered the pills \\
\hline Agent & $\mathrm{x}$ acts as [source-noun'] & We nerded out in this podcast. \\
\hline Performance & $x$ enacts [source-noun'] & They tangoed. \\
\hline Theme & $x$ causes [source-noun'] to go to or from a location & They mudded the walls. She shelled the nuts. \\
\hline Locative & $x$ causes y to go to [source noun'] & She bagged groceries. \\
\hline Instrument & x uses [source noun'] to perform some action & Sue hammered the metal flat. I ubered over to campus. \\
\hline
\end{tabular}

phrasal verbs with preposition-selections like get even (with), get back (at); support phrases like take revenge, wreak vengeance and exact retribution; nouns like vengeance, retribution, revenge; and several more (Andor 2010: 164; authors' emphasis).

If nouns, like verbs, evoke frames, then the semantic-role arrays that nouns have when converted to verbs have an obvious source: the frame or frames of the parent noun. In fact, the richness of the conceptual network in which a noun is embedded may be the reason the noun was a good candidate for conversion in the first place. According to the IDVC, a denominal verb can be classified according to the semantic role that the entity named by the source nominal plays in the event described by the sentence. Table 1 gives a partial list of these categories, adapted from Gottfurcht, 2008, and incorporating labels and categories from Clark and Clark (1979), Kiparsky (1997), Plag (1999), Lieber (2004).

In Table 1, informal event-structure descriptions are used to capture the participant role of the source-noun denotatum. This classification scheme implies that each denominal verb is uniquely classifiable as Theme, Locative, Instrument, etc., and that each verb's classification is predictable from criterial features of the source-noun category. Clark and Clark (1979: 789) postulate that when source nouns of denominal verbs are grouped according to salient physical characteristics (e.g., shape), ontogeny (e.g., material) and function, the resulting classes "correspond closely [...] with the classes and subclasses [arrived at in the] analysis of denominal verbs". For example, words that denote transportable objects (like water) commonly give rise to Theme verbs, words for shapes (like braid) commonly give rise to Result verbs, words for vehicles (like truck) commonly give rise to Instrument verbs, etc. Clark and Clark, however, see these salient features as subject to override in context:

To select the unique sense intended on a particular occasion, the listener must decide which of the possible senses is most salient. Generally [they] can look to the predominant features of the generic theory associated with the parent noun, which will always be fairly salient. But salience is a relative notion, and depends on context (Clark and Clark 1979: 795).

The denominal verb trash, for example is both a Result verb "turn $\mathrm{x}$ into trash" (e.g., I know you trashed my light-up Santa!) and a Theme verb "place trash in x" (e.g., Who is trashing the Columbia River gorge?). As shown in Table 1, there is typically more than one semantic dependent in a predication containing a denominal verb. For example, while the instumental denominal verb Uber evokes the vehicle used in an act of directed motion in $I$ ubered over to campus, it does so only in the context of a sentence in which the subject NP denotes the agent of that action and a directional PP denotes the goal of that action. This is so because predications express complex events involving motion (movement along a path) and causation (manipulation of entities, change of state/location). Studies in the tradition of semantic analysis pioneered by Clark and Clark (1979) offer insights into the mechanisms by which words referring to entities are integrated into contextually evoked event structures. Kiparsky (1997: 482) proposes an interpretive principle for denominal transfer verbs that "[i]f an action is named after a thing, it involves a canonical use of the thing". This principle could be used to explain why, for example, we would not refer to a tour guide allowing tourists inside a jail cell on Alcatraz Island as jailing the tourists (jail cells are designed to prevent suspected or convicted criminals from escaping). There are abundant exceptions to this principle, including the use of the denominal verbs egg and toilet paper, respectively, to the use of these items in acts of vandalism (e.g., Woke up one morning to a front yard that had been completely toilet papered). Noting that context may sometimes override subjects' object-affordance computations, Kaschak and Glenberg (2000) and Schönefeld (2018) conclude that the interpretation of a denominal verb relies on the grammatical construction in which it is embedded, especially in novel uses. Neuroimaging studies (e.g., Thierry et al., 2008) suggest that while subjects perceive novel denominal tokens from Shakespeare as formal anomalies (reading a novel denominal sentence triggers the P600 brainwave pattern associated with detection of wordinflection errors), such tokens are construed as semantically sensical, despite high integration costs (Thierry et al., 2008 find they also evoke the LAN brainwave pattern characteristic of revaluation of semantic content). This interpretive effort presumably involves a cascade of inferences. First, the interpreter must recognize that the noun in the context at hand has neither the syntactic behavior nor the ordinary referring properties of this noun lexeme. Second, cued by the syntactic context, the interpreter must retrieve the coarse eventstructure in which the entity denoted by the noun would play a semantic role. Third, the interpreter must identify the real or imagined entity that fills that semantic role. Fourth, the interpreter must find the rationale for the syntactic-category shift in question. This would involve constructing a specific scenario that adheres to the general schema "event initiated by causal agent." How might these inferences work in the case of the novel Herman Cain example in (1)? While Herman Cain is a proper name, its referential properties are overridden in this context, in which Herman Cain is the complement of the modal verb can. Herman Cain is not merely a verb in this context, but an agentive verb of removal, in particular ("verb the $x$ out of $y$ "). To 
translate our knowledge of the historic person Herman Cain into a Cain-type event, we must align entities from Cain's biography with verb roles: we identify the subject of the verb (George Wallace) with the agent of an act of destruction by artillery fire, the 8,000 stockpiled tweets with the ammunition and Twitter with the "place" being destroyed.

Understanding (1) requires an interpreter to combine disparate things: biographical details and semantic scripts of the kind that can be read off grammatical structure. This in turn suggests that interpreting a novel denominal verb is matter of optimization-finding the best fit between a nominal sign's constellation of semantic dependents and the syntactic pattern in which that sign is embedded. This procedure is neither pure syntax nor pure pragmatics. The purpose of this article is thus two-fold. First, we hope to show that neither rule-based nor mutual-knowledgebased approaches capture the combination of intrinsic factors (semantic properties of source nouns) and extrinsic factors (features of clausal and utterance context) that yield novel denominal interpretations. Second, we will demonstrate that a suite of analytic tools developed to model everyday language use and understanding provides a refined picture of the interpretive work that language users do when they encounter novel denominal verbs in context. For Clark and Clark, interpretations of denominal verbs either directly reflect predominant features of their source nouns or are ad hoc, derived from "moment-to-moment cooperation" including gestures, allusions, and "other momentarily relevant facts about the conversation" (1979: 783). We argue that denominal interpretations are more tightly regulated, and involve reconciling the results of four distinct interpretive strategies: nominal frame computation, verb-construction integration, co-composition and, finally, conceptual blending (including metaphorical mapping). One basic lesson for scholars of denominal meaning and use is that the nouns that become source nouns for innovative denominal formations are selected for this purpose because they are, in Fillmore's words, "semantically thick" - closely connected (through metaphor, metonymy, and other conceptual relations) to many other lexical concepts. Thus, denominal verb formation is not a matter of creating an argument structure for a noun, but rather one of exploiting semantic associates that the source nominal already has. Clark and Clark make much the same point, when they say that " $[\mathrm{m}]$ ost [denominal] verbs [...] should reflect the predominant features of the entities denoted by their parent nouns" (p. 793). The present work differs in its treatment of those innovative denominal formations whose interpretations come not from source-noun features, but rather from cues provided by the clausal context. The conventional denominal verb clock provides a simple illustration of this point:

2. Departure: I clocked out and gave Nancy my time card to cut me my last pay. (COCA) ${ }^{2}$

3. Measure: The radar clocked the pitch at $100 \mathrm{mph}$. (COCA)

\footnotetext{
${ }^{2}$ The tag COCA follows an example retrieved from the Corpus of Contemporary American English (Davies 2008), while the tag NOW indicates an example retrieved from the News on the Web corpus (Davies 2013).
}

4. Attack: Went upstairs, and I clocked the guy in the face. (COCA)

While (2-3) appear to belong to the Instrument class, (4) arguably belongs to the Locative class (with the locative source noun clock metaphorically representing a face). The distinct senses (departure, measure, attack) are products of syntactic context-the use of the directional particle out in (2), the use of a measure expression (at $100 \mathrm{mph}$ ) in (3), the animate direct object and body-part expression (in the face) in (4). While these verb senses derive from shared knowledge about clocks, they also rely on particular constellations of elements surrounding the verb.

The remainder of this article will be structured as follows. We will first discuss why derivational approaches (both transformational and lexical-rule-based) are unworkable, using attested innovative denominal verbs to illustrate (Why Derivational Approaches to Denominal Meaning do Not Work). Following this, we will discuss reasons to reject a strong view of context dependence, as represented by the IDVC (What the IDVC Does Not Capture). In Tools for Verbing Analysis, we will outline the integration-based approach to denominal interpretation by bringing to bear a suite of analytic tools developed to model everyday language understanding: Construction Grammar (Michaelis, 2004; Goldberg, 2006; Michaelis, 2011), co-composition (Pustejovsky, 1998; Pustejovsky, 2012), Conceptual Blending Theory (Fauconnier and Turner, 2004), and Frame Semantics (Fillmore, 2006; Andor, 2010). We will then provide extended illustrations involving three innovative denominal formations, two of which are Shakespeare coinages of the type noted by Thierry et al., 2008 (Application). A brief conclusion (Discussion) follows.

\section{WHY DERIVATIONAL APPROACHES TO DENOMINAL MEANING DO NOT WORK}

An influential account of denominal verbs treats them as the output of a syntactic derivation in which the constituent containing the source noun is adjoined to an unpronounced head verb representing a causal action (Hale and Keyser, 1993; Hale and Keyser, 2002). Sentence (5), for example, is said to be derived from (6) via movement of the PP in the corral to the head position of the verb, where it forms a compound verb (put-in-thecorral), thus deriving the denominal corral:

5. They corralled the mustangs.

6. They put the horse in the corral.

In this account, the most embedded constituent, corral, provides the phonological material for the matrix verb, and semantic conditions prohibit the overt instantiation of the incorporated constituent (as in, e.g., ${ }^{\star} J o h n$ corralled the horse in the corral). The incorporation account is implausible in numerous respects (McIntyre, 2016). For instance, in the attested I know how to canoe a canoe (COCA), the oblique 
locative expression is overtly instantiated despite its putative incorporation into the noun. A collateral concern is just what happens to the prepositional head in the course of the derivation. An additional issue, noted by both Harley (2005), Rimell (2012), is that the account must assume incorporation of adjunct NPs, which are not sisters to the verbal head in configurational syntax, in order to represent instrumental denominals like hammer and drill. Another issue concerns the status of agent denominals like parent (one's children), captain (the ship), and parrot (propaganda). As McInytre (2016) observes, agent denominals are unpredicted because incorporation of specifiers (subjects) is barred by the Hale and Keyser account.

A lexical-rule-based account of denominal formation proposed by Michaelis and Ruppenhofer (2001) faces its own problems. According to their proposal, the derivation that creates a verb from a noun preserves the frame-semantic structure of the source noun: arguments may be added to the source noun in the course of this derivation but not removed. Denominal cases like those in (7-8) show that the argument roles selected by source nouns and their corresponding derived verbs may differ in a way that undermines a derivational view:

7. In January, someone keyed her car and her husband's truck (NOW)

8. The new laws would increase penalties for drivers who door a cyclist (NOW)

Both (7) and (8) are self-evident exceptions to Kiparsky's canonical-use constraint. Neither denominal formation describes a canonical use of the source-noun referent (key, door). The frame-semantic analysis of key involves an agent who gains access via an instrument to a location. It does not include causing damage to a car. By the same token, the FrameNet analysis of door, based on the frames Connecting Architecture and Vehicle Subpart, does not include a cyclist victim. We will take up the semantic analysis of these cases in the sections below on cocomposition and conceptual blending.

\section{WHAT THE IDVC DOES NOT CAPTURE}

Our account draws heavily on the Clark and Clark approach, in particular in our emphasis on the manner in which novel denominal verb formations exploit relational properties of source noun denotations, as well as the manner in which contexts of use select the relevant relational properties. We differ in the way we characterize both the properties of nominal denotations and the selective contexts. Clark and Clark's focus is on predominant features (qualia) of commonnoun denotata. For example, they point out that the noun brick denotes a class of objects with a particular shape, function and material composition, and therefore that the sentence They bricked the ice cream could refer in various context to shaping the ice cream, using it as a structural component, placing it on a brick surface, smashing it with a brick, or even hardening it to a bricklike consistency. We view the properties not as features of nominal designata but rather as frame-semantic networks evoked by source nouns. Frame semantics is a theory of lexical structure rather than of criterial properties for category membership. We think the frame-semantic approach offers a more flexible way to describe the semantic dependents of denominal verbs formed from proper names, as in the Herman Cain example in (1) above. Herman Cain is not a category of things but a historic person, whose biography contains various frames of the type recognized by FrameNet, including Personal Success (Person), Political Actions (Activist), Communication (Communicator), Death (Protagonist), and Revenge (Avenger). It is the clausal syntax that in (1) instructs us to foreground the Avenger role, and to evoke additional roles, Weapon, and Offender, that also map to grammatical roles in the clause. We thus view selective contexts not as particular conversational contexts but rather as syntactic constructions that trigger analogical processes like metaphorical mappings. In this connection, it is critical to note that the IDVC is incorrect in one of its crucial particulars. A major tenet of the IDVC is that "the parent noun denotes one role in the situation, and the remaining surface arguments of the denominal verb denote other roles in the situation" (Clark and Clark 1979: 787). This rule is inapplicable to agentive denominals like (9):

\section{Davis apprenticed with Francis Ford Coppola (COCA)}

The parent noun apprentice in (9) does not denote the agent role; rather, this role is expressed by the subject NP, Davis. In a frame-semantic approach, source nouns do not denote roles. Rather, they evoke semantic frames, which are defined as constellations of roles. The syntactic expression of these roles is the job of argument-structure constructions, not "context" in a general sense.

Denominal interpretation and syntactic profile are so tightly connected that a denominal reading is often unavailable except in a single argument-structure configuration. This is so for Agent denominals nerd out, geek out and freak out, all of which require the particle out despite differing in transitivity; the Theme denominals suit up, gown up and mask up, all of which require the particle up, and the Agent denominal boss, typically transitive and paired with the particle around, e.g., Our leaders bossed around the world. These syntactic facts do not follow from criterial features of the source noun denotata, nor does the fact that several of these denominal verbs are exclusively figurative (e.g., a person who bosses someone else around is not a literal boss). Such findings suggest we must combine syntactic, semantic and pragmatic approaches to the interpretation of novel denominal verbs, to capture the interplay of event structure, metaphor and linguistic convention.

\section{TOOLS FOR VERBING ANALYSIS}

In this section we will outline the integration-based approach to denominal interpretation by describing a suite of analytic tools developed to model everyday language understanding: Construction Grammar (Michaelis, 2004; Goldberg, 2006; Michaelis, 2011), co-composition (Pustejovsky, 1998; Pustejovsky, 2012), Conceptual Blending Theory (Fauconnier 
TABLE 2 | Argument-structure constructions (adapted from Goldberg 1995)

\begin{tabular}{lll}
\hline Construction type & Argument structure & \multicolumn{1}{c}{ Semantic properties } \\
\hline INTRANSITIVE & $<\mathrm{NPX}>$ & $\mathrm{X}$ acts in some manner \\
DIRECTED MOTION & $<\mathrm{NPX}, \mathrm{PPy}>$ & $\mathrm{X}$ moves toward $\mathrm{Y}$ \\
SIMPLE TRANSITIVE & $<\mathrm{NPX}, \mathrm{NPy}>$ & $\mathrm{X}$ acts on $\mathrm{Y}$ or $\mathrm{X}$ experiences $\mathrm{Y}$ \\
DITRANSITIVE & $<\mathrm{NPX}, \mathrm{NPy}, \mathrm{NPZ}>$ & $\mathrm{X}$ causes $\mathrm{Y}$ to receive $\mathrm{Z}$ \\
CAUSED-MOTION & $<\mathrm{NPX}, \mathrm{NPy}, \mathrm{PPZ}>$ & $\mathrm{X}$ causes $\mathrm{Y}$ to move to $\mathrm{Z}$ \\
RESULTATIVE & $<\mathrm{NPX}, \mathrm{NPy}, \mathrm{XPZ}[\mathrm{PRD}+]>$ & $\mathrm{X}$ causes $\mathrm{Y}$ to become $\mathrm{Z}$
\end{tabular}

and Turner, 2004), and Frame Semantics (Fillmore, 2006; Andor, 2010). We believe that these tools help us to describe both novel and entrenched denominal verbs that exhibit certain puzzling properties. The denominal verb railroad, as in (10), illustrates these properties. Each property is listed below along with the analytic tool meant to address it:

10. They sort of felt like Steve Jobs had railroaded them into that deal. (COCA)

- Argument structure: The verb railroad is syntactically restricted: it is invariably found in the causative pattern shown in (10), with a PP headed by into and a noun or gerund denoting an intentional act.

- Frame semantics: While railroad could be regarded as an Instrument denominal ("transport x by railroad") it is used only figuratively in COCA, to mean "to induce $\mathrm{x}$ to act forcibly."

- Co-composition: Relatedly, the theme argument (direct object) of railroad in COCA is always an intentional actor, never, e.g., supplies or other resources that could be transported by railroad.

- Blending: While causes are commonly viewed as forces, ${ }^{3}$ the metaphor underlying the verb railroad does not preserve many aspects of source-domain structure: people ride on trains rather than being pushed by trains along a railroad track.

We describe each of these tools in what follows.

\section{Construction Grammar and Constructional Accommodation}

In Construction Grammar (CxG; Goldberg 1995; Michaelis 2004), the meaning of a sentence is determined by the combination of the lexical verb's core meaning with the basic event type (constructional meaning) conveyed by the construction with which the verb combines, referred to as an argument-structure construction (ASC). For our purposes, ASCs may be viewed as phrasal templates with verbal heads. Table 2 shows major English ASCs.

When a verb combines with an ASC, its semantic roles are identified or "fused" with the semantic roles each ASC assigns.

${ }^{3}$ See the MetaNet entry at https://metaphor.icsi.berkeley.edu/pub/en/index.php/ Metaphor: CAUSES_ARE_FORCES.
Verbs may combine with ASCs to which they are semantically mismatched, resulting in augmentation of the verb's "native" array of semantic roles. A commonly cited case involves the integration of an intransitive verb with the Caused Motion construction:

11. Liberty swam.

12. ${ }^{\star}$ Liberty swam the woman.

13. Liberty swam the woman to shore.

Examples (11) and (12) suggest that verbs like swim are used only in intransitive environments. How can we square this with examples like (13), in which the verb combines with a direct object and a directional expression? The syntactic flexibility illustrated by (13) is prevalent in English; creating a new lexical entry for each novel verb use (e.g., a trivalent caused-motion version of swim) would introduce pointless redundancy, and it would not capture the insight that many novel verb uses are nonce uses: they serve an expressive purpose in a particular context but may never become conventionalized. Using CxG tools, we account for this aspect of linguistic creativity in an intuitive way: ASCs have their own meanings and semantic role arrays, and the kind of event or relation expressed by a verb is ultimately determined by the ASC in which that verb is embedded. The application of this analysis, sometimes referred to as a constructional accommodation analysis, to the conversion strategy that produces denominal verbs is straightforward: the language user combines a noun like oil with an ASC like the Simple Transitive construction, and the word gains the combinatoric behavior characteristic of the simple transitive verb class. The ASC has a dispositive role in interpretation when the source noun participates in multiple frames. One such case is the noun water. When an agent is in the subject, water belongs to the Irrigation frame (e.g., I watered the roses). When a source argument is the subject, water belongs to the Secretion frame (e.g., My mouth/eyes watered). In the accommodation-based view of denominal verb formation, there is no special derivational rule for denominals; denominal verb formations are instead byproducts of the ordinary significations of ASCs. This does not mean that the source noun gets its argument array wholly from the ASC with which it combines. As in cases of valence augmentation like (13), those arguments licensed by the input lexeme (whether noun or verb) fuse with arguments of the construction. Sentence (14) shows a case of valence augmentation involving the denominal door from (8) above: 
14. Taxi passenger didn't see cyclist who was doored into path of van (NOW)

Sentence (14) combines the transitive verb door with the (passive) Caused Motion construction, from which the verb door gains a directional argument. The result of this combination is the fusion of the "victim" participant from door with the "theme" participant from the Caused Motion construction.

It is important to note that while the majority of denominal verb types (and tokens) are simple transitives (Rimell, 2012), referring, in Kiparsky's words, to "generically intentional activities" (1997: 476), the referential meaning of the source nominal is attenuated to the point that a participant role of the same type as the source nominal may be expressed as an oblique argument: She buttered her bread with apple butter, She shelved the books on the window sill. In this connection, it is important to recall from above (What the IDVC Does Not Capture) that source nouns do not denote roles. Rather, they evoke semantic frames, defined as constellations of roles. Each of these roles is expressed by an argument of the denominal verb.

\section{Co-Composition}

According to Pustejovsky (1998), Pustejovsky (2012), cocomposition is a form of enriched composition in which the operand (argument) contributes information to the operator (verb). Unlike argument selection, co-composition is a semantic two-way street: just as a verb exhibits selectional restrictions (e.g., requiring animacy, volition of the subject argument) so an otherwise inappropriate argument may modulate the meaning of the verb. Formally, co-composition involves a process in which conventional function application from an anchor function (e.g., the governing verb), along with ampliative information supplied by a triggering argument type, co-specifies the functor. Informally, co-composition is defined as the introduction of new information to a verb by the qualia of an argument selected by that verb. A classic example is the modulation of the verb bake by its direct object: if a cake is the direct object, the verb is interpreted as a verb of creation; if $a$ potato is the direct object, the verb is interpreted as a causative change-of-state verb. Our denominal verb key illustrates the use of co-composition as an interpretive strategy. As an Instrument denominal whose source nominal denotes a tool used to gain access, key is expected to combine with direct objects denoting portals and contained areas, as in, e.g., He keyed the door open and went in (COCA). When combined with direct objects denoting etchable surfaces, however, key denotes acts of scoring. It is through conceptual blending that we understand such acts to be acts of vandalism.

\section{Conceptual Blending Theory}

Conceptual Blending Theory (CBT; Fauconnier and Turner, 2004) assumes that meaning construction involves the selective mappings of elements across distinct conceptual domains (as in Lakoff's (1993) conceptual metaphor theory), as well as exploitation of inferences that derive from the mapping, and are not valid in any of the domains that are input to the mapping. It represents this construal process through a conceptual integration network that includes two input spaces: a generic space that represents what is common to the two input spaces, and a blended space. Input spaces are mapped to each other and projected selectively onto the blended space, which represents emergent properties and inferences not proper to either of the input spaces. A favorite illustration is metaphoric statement That surgeon is a butcher. Clearly there is structure common to each of the input domains of surgery and butchery: both types of entities cut flesh in hygienic settings. This shared structure is captured by the generic space. The blended space represents the properties that make the blend informative but are not attributable to either input space independently: this surgeon has low skill, does not adhere to professional standards, and causes injury. To illustrate the application of the CBT framework to innovative denominal verb formations, let us use it to analyze the innovative denominal formation in (15), from a January 2020 tweet:

15. also, i hate bernie sanders and all the other democratic politicians because i'm a principled black marxist, so none of you silly liberals can berniebro me.

While Berniebro is a compound noun that typically refers to an ardent male supporter of progressive presidential candidate Sen. Bernie Sanders, these referential properties are overridden in this context, in which Berniebro is the complement of a modal verb. Berniebro is not merely a verb in this context, but an agentive transitive verb in particular: the subject of this verb is understood to be an agent acting in line with whatever intentions are consistent with being a Berniebro, and the object of the verb $(m e)$ is understood to refer to a person who might be targeted by a Sanders advocate for online intimidation. Within frame-based semantic analysis, Berniebro is a role-designating noun, as it is embedded in a political advocacy frame that includes an organized or grassroots grouping of likeminded voters, openly professed beliefs, pursuit of political influence, favored candidates. The argument structure of the denominal verb Berniebro is derived from this (nominal) frame's semantic dependents. In (15), we can imagine two input spaces: the Berniebro frame evoked by the input noun (ardent political advocacy for Sanders by young, white, male would-be class warriors) and the coarse-grained event structure associated with the Simple Transitive construction ( $\mathrm{x}$ acts upon $\mathrm{y}$ ). The generic space captures the bivalent nature of the events in these two respective input spaces: (1) political supporter intimidates opponent and (2) agent acts on patient. The blended space represents the result of the reconciliation procedure that combines the two spaces: vociferous political advocacy, male posturing and low tolerance for dissent, on the one hand, and online bullying, on the other.

Blending resolves certain denominal puzzles, including the meanings of door and key, as in (7-8), repeated here as (16-17):

16. In January, someone keyed her car and her husband's truck (NOW)

17. The new laws would increase penalties for drivers who door a cyclist (NOW) 
Knowing the meanings of key and door, one would not necessarily guess that (16) describes an act of vandalism and (17) an act of causing injury in traffic. The FrameNet frame for key (called Key) includes an agent who gains access via an instrument to a location; it does not include a surface scored by a key, but this is what the direct object denotes in (16). Similarly, the FrameNet analysis of door is based on the frames Connecting Architecture and Vehicle Subpart, but does not include a victim role, as expressed by the direct object in (17). We assume a conceptual blend in both cases - in the case of key, a blend of the Key frame (use of implement) and the Damaging frame, and in the case of door, a blend of the Vehicle Subpart and Experience Bodily Injury frame. In each case, the blend is triggered by the use of the Transitive construction, which contributes a direct object, denoting the patient role, to each verb.

\section{Frame Semantics}

According to Frame Semantics, word meanings are schematizations of recurrent experiences, packaged as scenes with small arrays of semantic dependents. Fillmore offered the following frame-semantic discovery procedure to his students: imagine that you want to film a movie of a particular lexical unit; how many actors would you have to hire? But in addition to participants, frames may contain relations (e.g., part-whole relations), evaluations (for Fillmore, stingy, and thrifty as two different frames for reluctance to spend), presuppositions (Fillmore proposed that the "verbs of judging" praise and credit are distinguished by the fact that praise asserts goodness of the prior act while credit presupposes it), and perspectives (e.g., coast vs. shore). The prevalence of metaphorical mappings ensures that many lexical units belong to multiple frames, as when words from the Manual Manipulation frame like grasp recur in the Understanding frame. The same can be said of metonymic reference, the basis for eponymous denominal verbs like FedEx (e.g., Can you FedEx it?). Critical for our purposes is the insight that nouns and verbs have largely isomorphic framebased representations. As Fillmore puts it (Andor, 2010: 164):

In some cases the lexical unit (or the phrase that it syntactically heads) also stands for a frame element. This is especially true of role-designating nouns: a noun like guard evokes a frame of someone guarding some object or place, and at the same time it stands for an individual that holds such a role...

In other words, while the argument-structure constructions used to create denominal verbs are verb templates, and realize the source noun's semantic dependents as grammatical relations (subject, object, oblique), a denominal verb, particularly an innovative one, makes sense because we know the story that its source noun tells. Michaelis and Ruppenhofer (2001) make this same point with respect to German applicative (or be-) verbs derived from nouns, e.g., beschildern (lit. "be-signpost"). Similarly, the English nouns text, message, and signal (members of the Communication frame) have the frame elements Message, Addressee and Communicator whether noun or a verb, e.g., $I$ (Communicator) texted them (Addressee) that I was running late (Message). But while the noun may only express one of these roles (as in, e.g., my (Communicator) message, the message to you (Addressee), the message that I was running late (Message), a noun once embedded in an ASC can express all of the participant roles at once.

Treating denominal verbs requires us to broaden the class of relational nouns to include those that have the semantic dependents they do only by virtue of metonymic reference (Kövecses and Radden, 1998). One such case is the verb gaslight, meaning "cause someone (particularly an abuse victim) to doubt their own sanity or perceptions":

18. Most cheaters will lie and gaslight you unless you catch them dead to rights... (COCA)

The source noun gaslight is a relational noun because it is a metonym: it refers to the major instrument of deception in the 1944 thriller of the same name. In the film, an abusive husband uses various means to deceive the protagonist, Paula, into believing that she is going mad, in order to institutionalize her and gain access to jewels he believes she has hidden. He causes the gaslights in the house to flicker and dim at random times; when Paula reports these events, her abuser claims she is imagining them. While few who now use the verb gaslight know of the film, learning of the film provokes an "aha" reaction in many: the verbal coinage makes sense because the film scenario enables us to envision gaslight as a relational concept, with a deceiver, a falsehood, some ground truth, and a victim as its semantic dependents, as in (19):

19. My husband gaslighted me into believing we were broke (NOW)

Interpreting (19) requires us to envision a scene that combines the Caused Motion construction, metonymic source-noun frame semantics and the mechanism of blending (of film and reality).

\section{APPLICATION}

Here we apply the analytic tools developed in the section Tools for Verbing Analysis to a trio of innovative denominal verbs, including two nonce formations from the works of Shakespeare, a prodigious verb coiner (Thierry et al., 2008). We start with a fairly new but relatively entrenched coinage.

\section{Stan}

This verb is an agentive denominal formation, illustrated in (20):

20. Maybe if we were supported and stanned like yall stan Drake and Rihanna we would have the money to help (NOW)

Like many denominal person references, this verb refers to characterological figure: an obsessive fan (in this case, the psychotic stalker of Eminem's epistolary 2000 rap song "Stan"). What is striking about the verb stan is that it refers to a harmless variety of ardent fan support (especially as expressed in internet Fanboy/Fangirl culture), although one that can turn to online bullying in case of a perceived offense against the celebrity object of adoration. Below is a schematic representation of (20): 
- ASC: Transitive

- Experiencer: Addressee

- Patient: Drake, Rihanna, etc.

- Conceptual Blend

- Input space 1: Admiration

- Input space 2 (Transitive ASC): Ardent support

- Generic space: Affective state

- Blended space: Admiration is a sustained (and sustaining) emotional experience

- Source nominal frame: Via metonymy, the Experiencer Focused Emotion frame, with frame elements Experiencer and Content.

\section{Medicine}

This instance can be classified as an instrumental denominal. It comes from Iago's description of Othello's plight:

21. Look, where he comes. Not poppy nor mandragora. Nor all the drowsy syrups of the world, Shall ever medicine thee to that sweet sleep Which thou owedst yesterday (Othello III, 3). Below is a schematic representation of the contributors to meaning construction of (21):

- ASC: Caused Motion

- Agent: opioid syrup

- Patient: the addressee (Othello)

- Goal: sleep

- Conceptual Blend

- Input space 1: Hypnotic drugs/sleep aids

- Input space 2 (Caused Motion ASC): The metaphorical mappings STATES ARE LOCATIONS and CAUSES ARE FORCES (Lakoff 1993)

- Generic space: Change of state, causation

- Blended space: Opioids are the patient's means of transit to a somnolent state; patient unable to achieve transport to somnolent state

- Source nominal frame: The Cure frame (a Healer treating and curing an Affliction of the Patient, sometimes also mentioning the use of a particular Treatment or Medication)

\section{Boy}

Like stan, this denominal formation is an agentive denominal. It comes from a passage of Antony and Cleopatra in which Cleopatra imagines ridicule and humiliation that may await her in Rome:

22. Antony/Shall be brought drunken forth, and I shall see/Some squeaking Cleopatra boy my greatness/I' the posture of a whore (Antony and Cleopatra V, 2)

- ASC: Simple Transitive

- Agent: Boy actor who plays Cleopatra

- Patient: Cleopatra's greatness

- Conceptual Blend

- Input space 1: Boyhood

- Input space 2 (Transitive ASC): Parody performance (actors play historic persons)

- Generic space: Caricature (boy actor maps to female public figure)
- Blended space: The Elizabethan playing company, impersonation of a public figure, misgendered portrayal in a parody performance, diminution of public figure's stature

- Source nominal frame: The Parody frame (Actor gives caricatured Performance of Public Figure).

This example features referential opacity, which we expect to see in cross-world mappings of the type that feature in conceptual blends. The names Antony and Cleopatra in the passage refer not to the historic persons as portrayed in the play but instead to the actors who play them. As Fauconnier and Turner (2004) point out, this metonymic reference is of a conventional type [as in, e.g., Caesar (actor) was not bald enough to play Caesar (historic person)]. An additional observation concerns the semantic dependents of the noun boy, which presumably do not include "people or traits that a boy might portray if working as an actor". Where does the direct object of the denominal verb boy (my greatness) come from? The short answer is: from the blended space rather than from either input space. Even given the then-current understanding of acting troupes, presumably based on the Elizabethan playing company (Kathman, 2005), we would not wish to claim that "acting" belonged to readers' frame-semantic conception of boy. But blending can promote the salience of participant roles that are not core members of the source nominal's frame. A case in point is the verb widow, which, when transitive typically has a subject referring to a causal event (e.g., The conflict has widowed 45,000 women) rather than, say, the spouse who dies. The cause of the spouse's death (e.g., warfare) is at best a peripheral member of the frame of the nominal widow (i.e. Personal Relationship) and yet when the verbal construction requires an agent, the nominal frame provides one.

\section{DISCUSSION}

Our thick descriptions of innovative denominal verbs demonstrate the application of interpretive strategies based on construction meaning, conceptual blending, co-composition and framesemantic meaning. We hope to have shown that a combination of these frameworks provides a good tool kit for analysis of denominal formation. The frame-semantic perspective in particular requires us to adopt a broad understanding of what a role-denoting nominal expression is. The essential lesson for scholars of denominal meaning and use is that the nouns that become source nouns for innovative denominal formations are selected for this purpose because they have rich encyclopedic meanings. Thus, denominal verb formation is not so much about creating an argument structure for a noun as it is about exploiting the rich network of semantic connections that the source nominal already has. The argument structure of a novel denominal verb comes from the nominal frame's semantic dependents, with the syntactic realization of those dependents determined by the argument-structure construction (e.g., Caused Motion) with which the noun combines. When we look at nouns and verbs through a frame-semantic lens rather than through a denotational one (according to which nouns refer to entities and verbs to properties and relations), the semantic distance traversed by a 
noun in the course of becoming a verb seems small. An important lesson, however, is that in a frame-semantic approach, source nouns do not denote participant roles. Instead, they call forth semantic frames-arrays of semantic dependents. The syntactic expression of these roles is the job of argument-structure constructions, not conversational context. Because argument-structure constructions denote coarse-grained event types like causation of motion, eventstructure construals can attach to denominal verbs that are not directly traceable to source-nominal frame semantics, as in the case of railroading someone into doing something. Beyond syntactic constructions, there are apparently ineffable interpretations that would seem to make novel denominals an extreme case of context dependence. These novel cases include door and key-seemingly

\section{REFERENCES}

Andor, J. (2010). Discussing Frame Semantics: The State of the Art. Rcl 8, 157-176. doi:10.1075/rcl.8.1.06

Batty, C. (2008). Grice, "Meaning". Handout, Philosophy 515. University of Kentucky. Available at: http://www.uky.edu/ cebatt2/teaching/PHI_565_ Sept2008/PHI_565_Grice1. doi:10.1007/978-1-137-05057-1

Clark, E. V., and Clark, H. H. (1979). When Nouns Surface as Verbs. Language 55, 767-811. doi:10.2307/412745

Davies, M. (2013). Updated Every Day Corpus of News on the Web (NOW): 3+ billion words from 20 countries. Available at: https://www.english-corpora.org/.

Davies, M. (2008). The Corpus of Contemporary American English. Available at: www.english-corpora.org/coca/

Fauconnier, G., and Turner, M. (2004). The Way We Think. New York: Basic Books.

Fillmore, C. J. (1969). “Types of Lexical Information," in Studies in Syntax and Semantics. Editor F. Kiefer (Dordrecht: Springer), 109-137. doi:10.2514/ 6.1969-578

Fillmore, C. J. (2006). "Frame Semantics," in Cognitive Linguistics: Basic Readings. Editor D. Geeraerts (Berlin: De Gruyter), 373-400. doi:10.1515/9783110199901.373

Fillmore, C. J. (1976). "Frame Semantics and the Nature of Language," in Annals of the New York Academy of Sciences: Conference on the Origin and Development of Language and Speech, 280, 20-32. doi:10.1111/j.1749-6632.1976.tb25467.x

Goldberg, A. (1995). Constructions: A Construction Grammar Approach to Argument Structure. Chicago: University of Chicago Press.

Goldberg, A. (2006). Constructions at Work: The Nature of Generalization in Language. Oxford: Oxford University Press.

Gottfurcht, C. A. (2008). Denominal Verb Formation in English. Unpublished PhD Dissertation. Northwestern University.

Grice, H. P. (1989). Studies in the Way of Words. Cambridge, MA: Harvard University Press.

Grice, H. P. (1957). Meaning. Philosophical Rev. 66, 377-388. doi:10.2307/2182440

Hale, K., and Keyser, S. J. (1993). "On Argument Structure and the Lexical Expression of Syntactic Relations," in The View from Building 20. Editors K. Hale and S. J. Keyser (Cambridge: MIT Press), 53-109.

Hale, K., and Keyser, S. J. (2002). Prolegomenon to a Theory of Argument Structure. Cambridge: MIT Press. doi:10.7551/mitpress/5634.001.0001

Harley, H. (2005). "How Do Verbs Get Their Names? Denominal Verbs, Manner Incorporation, and the Ontology of Verb Roots in English," in The Syntax of Aspect, 42-65. Editors N. Erteschik-Shir and T. Rapoport (Oxford: Oxford University Press).

Kaschak, M. P., and Glenberg, A. M. (2000). Constructing Meaning: The Role of Affordances and Grammatical Constructions in Sentence Comprehension. J. Mem. Lang. 43, 508-529. doi:10.1006/jmla.2000.2705

Kathman, D. (2005). "How Old Were Shakespeare's Boy Actors?," in Shakespeare Survey. Editor P. Holland (Cambridge: Cambridge University Press), 220-246. doi:10.1017/ccol0521850746.021

Kiparsky, P. (1997). "Remarks on Denominal Verbs," in Complex Predicates. Editors A. Alsina, J. Bresnan, and P. Sells (Stanford: CSLI Publications), 473-499. ordinary denominal verbs that take extraordinary direct objects in our corpus data: a cyclist victim in the case of door and a scratchable surface in the case of key. We do not define doors as causes of injury or keys as instruments of vandalism. But the relevant denominal interpretations do not come from nowhere. They are products of co-composition and conceptual blending.

\section{AUTHOR CONTRIBUTIONS}

LM performed analyses and drafted the text. $\mathrm{AH}$ performed research, including corpus extraction, summarized secondary sources, provided insights and discussion throughout.

Koutsoukos, N. (2021). Denominal Verb Formation in English and Modern Greek. Lang. Contrast 21, 138-161. doi:10.9771/aa.v0i61.39121

Kövecses, Z., and Radden, G. (1998). Metonymy: Developing a Cognitive Linguistic View. Cogn. Linguistics 9 (1), 37-78. doi:10.1515/cogl.1998.9.1.37

Lakoff, G. (1993). “The Contemporary Theory of Metaphor," in Metaphor and Thought. Editor A. Ortony (Cambridge: Cambridge University Press), 202-251. doi:10.1017/cbo9781139173865.013

Lieber, R. (2004). Morphology and Lexical Semantics. Cambridge: Cambridge University Press.

McIntyre, A. (2016). Denominal Verbs: An Overview. Word-Formation: An International Handbook of the Languages of Europe, 1406-1423.

Michaelis, L. A., and Ruppenhofer, J. (2001). Beyond Alternations: A Constructional Approach to the Applicative Pattern in German. Stanford: CSLI Publications.

Michaelis, L. A. (2004). Type Shifting in Construction Grammar: An Integrated Approach to Aspectual Coercion. Cogn. Linguistics 15, 1-67. doi:10.1515/ cogl.2004.001

Michaelis, L. A. (2011). Stative by Construction. Linguistics 9, 1359-1399. doi:10.1515/ling.2011.038

Morgan, J. L. (1978). "Two Types of Convention in Indirect Speech Acts," in Pragmatics. Editor P. Cole (New York: Academic Press), 261-280.

Plag, I. (1999). Morphological Productivity: Structural Constraints in English Derivation. Berlin: Mouton de Gruyter.

Pustejovsky, J. (2012). Co-compositionality in Grammar. The Oxford Handbook of Compositionality 371, 382. doi:10.1093/oxfordhb/9780199541072.013.0017

Pustejovsky, J. (1998). The Generative Lexicon. Cambridge, MA: MIT Press. doi:10.7551/mitpress/3225.001.0001

Rimell, L. (2012). Nominal Roots as Event Predicates in English Denominal Conversion verbs. Unpublished PhD Dissertation. New York University.

Schönefeld, D. (2018). Friending Someone into Submission: Verbal Cues for Understanding. Word Struct. 11, 211-237. doi:10.3366/word.2018.0125

Searle, J. (1975). "Indirect Speech Acts," in Speech Acts. Editors P. Cole and J. Morgan (New York: Academic Press), 59-82.

Thierry, G., Martin, C. D., Gonzalez-Diaz, V., Rezaie, R., Roberts, N., and Davis, P. M. (2008). Event-related Potential Characterisation of the Shakespearean Functional Shift in Narrative Sentence Structure. Neuroimage 40, 923-931. doi:10.1016/j.neuroimage.2007.12.006

Valera, S. (2015). "Conversion," in Word-Formation. An International Handbook of the Languages of Europe. Editors I. Müller, I. Ohnheiser, S. Olsen, and F. Rainer (Berlin: Mouton De Gruyter), Vol. 1, 322-339.

Conflict of Interest: The authors declare that the research was conducted in the absence of any commercial or financial relationships that could be construed as a potential conflict of interest.

Copyright (c) 2021 Michaelis and Hsiao. This is an open-access article distributed under the terms of the Creative Commons Attribution License (CC BY). The use, distribution or reproduction in other forums is permitted, provided the original author(s) and the copyright owner(s) are credited and that the original publication in this journal is cited, in accordance with accepted academic practice. No use, distribution or reproduction is permitted which does not comply with these terms. 